Revue bibliographique pour le domaine irano-aryen

\title{
Lori Khatchadourian. Imperial Matter. Ancient Persia and the Archaeology of Empires
}

\section{Sébastien Gondet}

\section{(2) OpenEdition}

12 Journals

\section{Édition électronique}

URL : http://journals.openedition.org/abstractairanica/47341

DOI : 10.4000/abstractairanica.47341

ISBN : 1961-960X

ISSN : 1961-960X

Éditeur :

CNRS (UMR 7528 Mondes iraniens et indiens), Éditions de l'IFRI

Référence électronique

Sébastien Gondet, "Lori Khatchadourian. Imperial Matter. Ancient Persia and the Archaeology of Empires », Abstracta Iranica [En ligne], Volume 37-38-39 | 2018, document 98, mis en ligne le 30 décembre 2018, consulté le 26 septembre 2020. URL : http://journals.openedition.org/ abstractairanica/47341 ; DOI : https://doi.org/10.4000/abstractairanica.47341

Ce document a été généré automatiquement le 26 septembre 2020.

Tous droits réservés 


\title{
Lori Khatchadourian. Imperial Matter. Ancient Persia and the Archaeology of Empires
}

\author{
Sébastien Gondet
}

\section{RÉFÉRENCE}

Lori Khatchadourian. Imperial Matter. Ancient Persia and the Archaeology of Empires. Oakland: University of California Press, 2016, xxxviii+288p., ISBN (papier) 9780520290525, ISBN (ebook) 9780520964952 (http://dx.doi.org/10.1525/luminos.13= Luminos Open Access Series)

1 Alors que son titre pourrait le laisser penser, l'objectif de cet ouvrage n'est pas vraiment de produire une monographie sur l'archéologie de l'empire achéménide. Il propose plutôt une nouvelle grille d'analyse des données matérielles en mobilisant des concepts travaillés par différentes écoles de pensées en vogue dans le milieu anglosaxon des SHS. Plus largement, l'A. se sert de la période achéménide comme d'un cas d'étude pour produire une réflexion sur le fait impérial et/ou colonial en général et ses conséquences sociopolitiques analysées à partir des sources matérielles. Bien que pouvant paraître par moment obscure, il faut saluer la démarche volontariste de l'A. qui cherche à dessiner une voie pour que l'archéologie participe plus activement et de manière plus autonome à l'écriture de l'histoire des empires en général et de l'empire achéménide en particulier.

2 Le livre est composé d'une longue introduction et de six chapitres divisés en deux grandes parties. La première partie du livre parle assez peu d'archéologie mais se veut très théorique. On retiendra toutefois un premier chapitre traitant de la condition satrapique, c'est-à-dire de la condition de sujet, dans l'empire achéménide. L'A. produit une réflexion originale sur le rôle du monde matériel dans la construction d'une cosmologie perse, les objets et les monuments royaux ainsi que leur matière première, 
en premier lieu le métal et la pierre, y jouant un rôle primordial. Le reste de cette première grande partie constitue une longue synthèse des récentes avancées quant à la place de l'objet, de l'inanimé, dans les études en sciences sociales. L'A. passe en revue les différentes approches issues des sciences politiques, de l'ethnologie, de la philosophie ou encore de la sociologie concernant la prise en compte du monde matériel pour analyser les processus de domination et d'acculturation au sein des ensembles impériaux. Bien qu'assez éloignés de l'archéologie strico sensu, ces différents chapitres (et surtout la seconde partie du chap. 3) sont toutefois nécessaires pour comprendre l'analyse produite dans la seconde grande partie du livre qui, elle, traite plus spécifiquement d'archéologie. L'A. introduit en effet l'ensemble des concepts et définit une grille d'analyse des données archéologiques qu'elle utilisera pour dessiner les contours d'une étude en sociologie politique de l'empire achéménide.

3 La seconde partie du livre n'apporte que peu de données archéologiques nouvelles au lecteur. Elle consiste avant tout en un essai de réinterprétation de données archéologiques déjà connues et publiées. Elle s'ouvre sur un réexamen d'une question maintes fois abordées: l'apparition de la salle hypostyle dans le monde mède et sa réappropriation par le pouvoir achéménide comme marqueur et lieu d'exercice par excellence du pouvoir royal. Dans les deux chapitres suivants, l'A. porte son regard vers le Caucase, l'ancienne province d'Arménie, où elle a participé à plusieurs projets archéologiques au cours des deux dernières décennies. Après avoir brossé un tableau de l'évolution des stratégies d'occupation du territoire caucasien au cours du $1^{\mathrm{er}}$ millénaire, l'A. passe en revue les différents éléments matériels qui illustrent l'intrusion de normes perses dans la province d'Arménie. Elle analyse plusieurs ensembles de contenants en argent retrouvés, ou supposés avoir été retrouvés, dans la région ainsi que les bâtiments à colonnes de la région, ceux des sites de Karačamirli (Knauss et al. 2013 [AI 34-36, $\mathrm{n}^{\circ}$ 89]) ou encore d'Erebuni (contra Deschamps et al. 2011 [AI 34-36, n 111] pour lesquels le bâtiment n'est plus utilisé à la période achéménide). Le livre se conclut sur un chapitre décrivant et analysant les données archéologiques mises au jour, entre 1998 et 2013, dans les niveaux achéménides du site de Tsaghkahovit situé au nord-ouest de l'Arménie actuelle. C'est dans cette partie que l'A. développe le plus minutieusement sa méthode d'analyse appliquée à un corpus matériel issu d'une installation rurale située aux confins de l'empire. L'analyse, à travers les données archéologiques, des dynamiques sociologiques à l'œuvre dans une communauté de pasteurs d'Arménie à l'époque achéménide présente ici un intérêt avant tout épistémologique. Si l'on s'intéresse uniquement aux données archéologiques mis au jour sur ce site, on se reportera plutôt à une autre publication récente et plus complète de la même A. (Cf. Khatchadourian 2014 [cr par R. Boucharlat dans le même volume]).

4 N.B. : le livre est librement dispponible en ligne à l'adresse suivante $h t t p: / / d x . d o i . o r g / 10.1525 /$ luminos.13 


\section{AUTEURS}

\section{SÉBASTIEN GONDET}

UMR 5133 CNRS-Université de Lyon 